\title{
Rumos da Educação em Saúde no Brasil e sua Relação com a Educação Ambiental
}

\section{Trends in Health Education in Brazil and Relationships with Environmental Education}

\author{
Adriana Mohr ${ }^{7}$ \\ Virginia T. Schall ${ }^{2}$
}

\begin{abstract}
MOHR, A. \& SCHALL, V. T. Trends in Health Education in Brazil and Relationships with Environmental Education. Cad. Saude Públ., Rio de Janeiro, 8 (2): 199-203, abr/jun, 1992.

A brief survey of the historical development of health education in Brazilian elementary schools leads to a critical evaluation of modern practices. The authors point to deficiencies in school facilities, in the quality of the available textbooks and in the training of school teachers. Some guidelines for future action are presented and briefly discussed.
\end{abstract}

Keywords: Education; Health; Health Education; Environmental Education; Elementary Education

Com a crescente preocupação do homem em relação às questões ecológicas e aos graves efeitos de sua ação predatória sobre o planeta e sobre a própria espécie, a atenção à saúde se volta para um contex to mais amplo, levando em conta as relações entre esta e o ambiente físico e social. Essa dimensão ambiental abrangente pode ser uma oportunidade para superar, de vez, o enfoque sanitarista tradicional da educação em saúde, restrita a práticas centradas unicamente em regras de higiene pública e individual.

\section{Antecedentes Históricos}

A análise histórico-crítica da educaçāo em saúde no Brasil apresentada na literatura demonstra que, desde o século XIX, a medicalização da vida social vinculava-se a um controle do Estado sobre os individuos, no sentido de manter e ampliar a hegemonia da classe dominante. Tal orientação foi reforçada pelas desco-

\footnotetext{
'Departamento de Ciências Biológicas da Escola Nacional de Saúde Pública. Rua Leopoldo Bulhōes, 1480 , Rio de Janeiro, RJ, 21041-210, Brasil.

'Laboratório de Educação Ambiental e em Saúde, Departamento de Biologia do Instituto Oswaldo Cruz. Caira Postal 926, 20001-970, Rio de Janeiro, RI, Brasil.
}

bertas bacteriológicas, reduzindo a doença a uma relação de causa e efeito de ordem estritamente biológica. Não eram consideradas, no seu contexto, a questão social nem o processo histórico de sua origem e manutenção (Loureiro, 1989).

Data da década de 1920 a criação da cátedra de higiene na Faculdade de Medicina do Rio de Janeiro (Peixoto, 1908). Também na mesma década, como aponta Lima (1985), houve o deslocamento da ação da polícia médica para a educação sanitária, através do modelo norteamericano. Antes disso, a questão da saúde na escola elementar era focalizada, no contexto da higiene escolar, de modo incipiente na segunda metade do século XIX, tornando-se institucionalizada, a partir da primeira década do século $\mathrm{XX}$, em alguns estados brasileiros.

A visão positivista subjacente era de que a educação poderia corrigir, através da higiene, a ignorância familiar que comprometia a saúde da criança, e de que a saúde individual era a base da estabilidade e segurança da nação. A escola não seria apenas o espaço de ensino, mas um agente terapéutico, recaindo sobre o professor a tarefa de transformar o mundo (Lima, 1985).

Na década de 1940, a ênfase recaiu sobre a educação rural, visando educar o homem do campo para garantir o aumento da produção 
pelas novas técnicas e máquinas agrícolas.

Segundo Melo (1987), entre as décadas de 1950 e 1960, houve um periodo áureo da educação sanitária no Brasil que articulava a saúde e a educação, integradas nas propostas das políticas oficiais. Isto resultou em avanços institucionais significativos em diversos campos, como a valorização da higiene mental, a implantação das escolas maternais, creches e parques infantis, dentre outros. Entretanto, todo este movimento se pautava por uma ideologia modernizadora, encaminhando a hegemonia da burguesia industrial no domínio estrutural da sociedade (Luz, 1981).

A pedagogia da saúde, de cunho modernizador, tinha por meta remover os obstáculos (culturais e psicossociais) às inovações tecnológicas de controle às doenças (Canesqui, 1984). A perspectiva de participação da comunidade nos processos de educação em saúde, da década de 1960 , visava mobilizar as populações a cooperarem com os agentes de saúde $e$ os serviços de saúde inaugurados nas zonas rurais e periferias urbanas. Entretanto, a centralização administrativa da politica nacional de saude ainda era dominante (Canesqui, 1984), e assim permaneceu até recentemente.

Durante os anos da década de 1970, após sucessivas reformas na área da política de saúde, a pedagogia de Paulo Freire era assimilada nas ações de saúde, embora não incorporada no contexto geral do país. Segundo Canesqui (1984), encontrando seus limites, esta pedagogia se reformulou, indo de encontro à saúde popular nas formas organizadas do movimento popular e ds metas gerais das camadas trabalhadoras, sem desprezo por suas condiçōes de vida e sauide.

Esses movimentos, comprometidos com as necessidades e possibilidades das classes populares, encaminharam uma nova articulação entre a educação e a saúde, onde, em paralelo à causalidade biológica, são consideradas as condições de vida e trabalho como fatores predisponentes essenciais.

\section{A Prática da Educação em Saúde nas Escolas}

A educação em saúde se tornou obrigatória nas escolas brasileiras de $1^{\ell}$ e $2^{q}$ graus pelo artigo 7 da lei 5.692/71, com o objetivo de estimular o conhecimento e a prática da saúde básica e da higiene. A própria operacionalização da lei, através do parecer 2.264/74 (Conselho Federal de Educação, 1974), estabelece que a aprendizagem deve se processar, prioritariamente, através de ações e não de explanações, o que não se efetivou de fato.

Exceção feita a alguns grupos de pesquisa $e$ escolas, a prática cotidiana da grande maioria das atividades escolares nestas áreas não produz resultados animadores. Tal situação pode ser atribuída a um conjunto de fatores, direta ou indiretamente, relacionados ao ambiente escolar. Cumpre sublinhar que tal quadro não é exclusivo dos temas aqui discutidos; antes, associa-se ao crítico panorama da educação nacional, sendo, ao mesmo tempo, conseqüência $e$, na parcela que the cabe, origem de tal situação.

A formação do professor nos domínios da educação ambiental e da educação em saúde é muito deficiente. Claro está que existem gradações nesta falta de preparo, mas, de maneira geral, podemos verificá-la tanto no professor oriundo das escolas de formação de professores, a nível de $2^{2} \mathrm{grau}$, quanto naquele que, licenciado, atingiu a formação universitária. Quando a formação teórica do docente, no seu campo de especialidade (ciências biológicas, por exemplo), é de sufiente qualidade, faltam-lhe conhecimentos teóricos e/ou práticos sobre procedimentos didáticos ou, ainda que estes sejam de seu domínio, dificuldades se colocam, impedindo-o de desenvolvê-los na realidade de sua classe. Os professores, via de regra, não se encontram preparados para organizar atividades de ensino a partir da análise de uma dada realidade concreta. Estudos de Moura (1990) e Schall et al. (1987a) demonstram a falta de formação teórica de professores em assuntos relacionados à educação em saúde.

Parcialmente decorrente da situação acima discutida, temos que o livro didático deixa de ser mais um entre os recursos didáticos disponiveis ao professor e passa a assumir o papel de único material presente na classe, sendo o principal suporte das atividades de sala de aula (Franco, 1982; Pondé et al., 1984; Moura, 1990). Barbieri (1992) comenta que freqüentemente, o professor descarta a licenciatura que cursou e fica com o livro didático. 
Neste contexto, a qualidade do livro didático deve ser considerada com muita atenção. Embora sejam raras as análises de livros didáticos que abordam a saúde, Alves (1987) e Vargas et al. (1988) demonstraram inadequações e incorreções do ponto de vista da metodologia e dos conteúdos que os compõem.

Vem somar-se à falta de excelência do livro didático a escassez de material de qualidade produzido para divulgação científica, o qual poderia suprir, com vantagens, a lacuna do livro didático.

Verifica-se, ainda, o regime de trabalho e de remuneração extremamente desfavoráveis a que está submetida a maioria dos docentes, bem como as condiçōes físicas desagradáveis, e até mesmo insalubres, a que foi reduzida a grande maioria das unidades escolares.

Completando o quadro, ressalta-se a breve vida escolar de grande parte da população brasileira, motivada entre outros fatores pela repetência e evasão escolar.

Desta forma, é deficiente a formação do indivíduo no que diz respeito a conceitos, processos e comportamentos envolvidos na manutenção ou recuperação da saúde individual ou coletiva.

A metodologia empregada e os conteúdos desenvolvidos nas atividades de educação em saúde na escola concorrem grandemente para esta situação. Vários estudos têm demonstrado que, geralmente, as atividades de educação em saúde na escola são desenvolvidas com conteúdos ultrapassados; às vezes deturpados (Schall et al., 1987b; Santos et al., 1990); apresentados de maneira estritamente teórica (Santos et al., 1990); desvinculados da realidade e necessidades dos alunos (Bastos, 1979; Candeias et al., 1980; Candeias, 1984; Ferraroti, 1984; Schall et al., 1987c) e inapropriados do ponto de vista da estrutura cognitiva da faixa etária às quais se destinam (Schall et al., 1987c). A metodologia das aulas, via de regra, baseia-se na exposição teórica e prescrição de regras que os alunos seriam compelidos a seguir (Schall et al., 1987 c). Some-se a isto o fato dos conhecimentos transmitidos basearem-se, quase que unicamente, em informações a respeito da descrição de agentes etiológicos, no ciclo das zoonoses e na sintomatologia das doenças, ignorando o desenvolvimento de conteúdos sobre processos e fatores condicionantes envolvidos na infecção, na doença e nos acidentes. Além disso, o programa de saúde, paradoxalmente, tem sua ênfase na doença e não na saúde.

Como resultado, verifica-se que os conhecimentos que são pretensamente desenvolvidos com os alunos não são traduzidos em comportamentos, seja por falta de condições de internalização dos conteúdos ou porque estes não possuem significado para a realidade do estudante.

\section{Novas Abordagens da Educação em Saúde}

$O$ desenvolvimento adequado das atividades de educação ambiental e de educação em saúde, tanto no espaço escolar como fora dele, com crianças e adultos, tem infinitas possibilidades, que devem ser estruturadas de acordo com cada situação em particular. Sem a intenção de traçar fórmulas, mas apenas assinalar algumas orientações, passamos a comentar os pontos abaixo.

As peculiaridades cultural e ambiental de cada comunidade exigem que todas as ações partam de tal especificidade e que a levem em consideração estrita. Campanhas de caráter nacional que desconsideram as particularidades regionais de nomenclatura atribuídas a vetores de doenças, por exemplo, ou ainda os hábitos culturais e sociais distintos de populações geograficamente próximas estão fadadas ao insucesso.

Da mesma forma, atividades desenvolvidas na escola, que têm por ponto de partida situações alheias à realidade vivida pelos seus alunos, desperdiçam tempo e oportunidades valiosas. $O$ mesmo ocorre quando se ignora o conhecimento popular acerca de determinada situação, desvalorizando-o e inferiorizando-o, ao invés de trabalhar junto e a partir dele.

Para se trabalhar efetivamente a saúde na escola é necessário, também, realizar cursos de atualização para professores que aperfeiçoem sua eficiência pedagógica e ampliem sua visão da questão da saúde nos seus múltiplos aspectos. Isto é essencial para o encaminhamento de uma ação participativa e criadora dos alunos. É importante estimular os professores a planejarem e executarem projetos em conjunto com seus alunos, investigando algum problema de saúde relevante para a região da escola e propondo ações e alternativas de solução. Tais 
projetos devem ser registrados e avaliados sistematicamente quanto à sua eficacia no àmbito escolar e fora dele.

Deve-se ter em mente, ainda, que o cientista produz conhecimentos especificos, $e$, habitualmente, a informação educacional tem derivado automaticamente dele. Mas, é conjuntamente com o conhecimento técnico que se gera um outro saber, que é o especificamente educacional. Tal processo exige, portanto, estudos especificos e um espaço próprio onde possa ser desenvolvido (Schall et al., 1992).

Muito comum é o desenvolvimento de atividades de educação ambiental ou de ecologia tomando-se como objeto de estudo prioritário o buraco de ozônio, o efeito estufa ou, ainda, florestas distantes, por exemplo. Negligencia-se o fato de que cada indivíduo está inserido em um ecossistema e que os princípios são gerais a todos. Partindo-se da realidade próxima, além do ganho qualitativo em trabalhar com algo que possua real significado para o estudante, tem-se a possibilidade de explorar $o$ ambiente $e$ as relações com a qualidade de vida nele praticadas. Isto é verdadeiro para as mais distintas realidades sócio-econômicas. Em escolas de favelas ou de periferias de baixa renda, poderiam ser desenvolvidas atividades que permitissem a compreensão da relação da prevalência das doenças gastrintestinais com a qualidade $e$ abastecimento (ou não) de água, ou ainda os problemas advindos da falta de disposição adequada dos esgotos e do lixo. Em se tratando de escolas que tivessem por clientela alunos da classe economicamente privilegiada, poder-se-ia questionar a produção doméstica do lixo e o desperdício gerado pelo consumo desenfreado.

Desta forma, a educação ambiental e a educação em saúde assumem um caráter muito mais amplo do que a mera (mas importante $e$ indispensável) aquisição de conhecimentos, passando a ser um momento de reflexão e questionamento das condições de vida, suas causas e consequiências, e se tornando um instrumento para a construção e consolidaçāo da cidadania.

Embora a exemplificação de todo o trabalho tenha sido, na sua maioria, com situações advindas do ambiente escolar (resultado da experiência e atuação das autoras), a presente discussão não se esgota ou se basta dentro da escola. São de fundamental importância as atividades desenvolvidas fora do contexto escolar, em associações de moradores, clubes de mães, postos de saúde, etc., e que são passíveis dos questionamentos aqui abordados. Também devem ser reavaliadas, levando-se em consideração as idéias expostas acima, as campanhas de controle e/ou erradicação de doenças veiculadas através dos meios de comunicação de massa, ou ainda os materiais produzidos para elas, como filmes, cartazes, folhetos, etc.

Esta é a direção da educação em saúde comprometida com a formação de um cidadão autônomo e crítico e, conseqüentemente, com uma ação transformadora para a melhoria das condições de vida.

\section{RESUMO}

MOHR, A. \& SCHALL, V. T. Rumos da

Educação em Saúde no Brasil e sua

Relação com a Educação Ambiental. Cad.

Saúde Públ., Rio de Janeiro, 8 (2): 199-203, abr/jun, 1992.

No presente trabalho são apresentados, brevemente, alguns antecedentes históricos da educação em saúde no Brasil, desde o final do século passado até os dias atuais, $e$ as diversas características de enfoque que tal campo possuiu ao longo do tempo.

Discorre-se sobre o atual quadro do ensino de saúde nas escolas brasileiras de $1^{2}$ grau, salientando-se e constatando-se o despreparo dos professores nesta área de conhecimento, a falta de qualidade da maioria dos livros didáticos disponíveis, a escassez de material alternativo a ele, as condições desfavoráveis de regime de trabalho dos professores e as péssimas condições físicas que apresentam, via de regra, as escolas de $1^{q}$ grau. Conclui-se apontando algumas idéias-chave para $o$ desenvolvimento da educação em saúde, levando em conta uma abordagem ambiental ampla.

Palavras-Chave: Educação; Saúde; Educação em Saúde; Educação Ambiental; Ensino de $1^{2}$ Grau 


\section{REFERÊNCIAS BIBLIOGRÁFICAS}

ALVES, N. C., 1987. A saúde na sala de aula: uma análise nos livros didáticos. Cadernos CEDES, 18: 38-53.

BARBIERI, M. R., 1992. Mais que uma alternativa ao livro didático. Passando a Limpo, 1: 13.

BASTOS, N. C. B., 1979. Educação para a saúde na escola. Revista da Fundação SESP, 24: 35-49.

CANDEIAS, N. M. F., 1984. Ensino da saúde: interesses na área de saúde de escolares adolescentes. Cadernos de Pesquisa, 50: 40-52.

CANDEIAS, N. M. F. \& MARCONDES, R. S., 1980. Identifying educational needs of schoolchildren in a secondary school in São Paulo. International Journal of Health Education, 23: 42-48.

CANESQUI, A. M., 1984. Trajetória da educação popular nas instituições estaduais de saúde. In: Perspectivas e Dilemas da Educação Popular (V. Paiva, org.), pp. 315-324, Rio de Janeiro: Edições Graal.

CONSELHO FEDERAL DE EDUCAÇÃO, 1974. Parecer $n^{2} 2.264 / 74$ - Ens. (1 $1^{2}$ e $2^{2}$ Graus). Documenta, 165: 63-81.

FERRAROTI, N. G., 1984. Educación para la salud en la adolescencia. Relato de una experiencia. Boletin de la Oficina Sanitaria Panamericana, 97: 240-250.

FRANCO, M. L. P. B., 1982. O livro didático de história do Brasil: algumas questões. Cadernos de Pesquisa, 41: 22-27.

LIMA, G. Z., 1985. Saúde escolar e educação. São Paulo: Cortez.

LOUREIRO, S.,1989. A questão do social na epidemiologia e controle da esquistossomose mansonica 1. Memórias do Instituto Oswaldo Cruz, 84 (supl.D): 124-133.

LUZ, M. T., 1981. As instituições médicas no Brasil: instituição e estratégia de hegemonia. 2" edição. Rio de Janeiro: Graal.

MELO, J. A. C., 1987. Educação sanitária: uma visão crítica. Cadernos do CEDES, 4: 28-64.

MOURA, E. C., 1990. Ensino da saúde no currículo de $1^{2}$ grau - subtema nutrição. Ciência e Cultu$r a, 42:$ 283-287.

PEIXOTO, A., 1975. Clima e Saúde. $2^{1}$ ed. São Paulo: Editora Nacional.

PONDÉ, G.; ALVES, N. \& ROLLIN, W., 1984. O livro didático na área de comunicação e expressão: algumas idéias. Leitura: Teoria e Práti$c a, 3:$ 26-32.

SANTOS, M. G. S.; MASSARA, C. L. \& MORAIS, G. S., 1990. Conhecimentos sobre helmintoses intestinais de crianças de uma escola de Minas Gerais. Ciencia e Cultura, 42: 188-194.
SCHALL, V. T.; BUROCHOVITCH, E.; FÉLIXSOUZA, I. C.; VASCONCELOS, M. C. \& ROZEMBERG, B., 1987a. Avaliação do conhecimento sobre doenças parasitárias entre professores e alunos do $1^{8}$ grau. Ciencia e Cultura, 39 (supl.): 160.

SCHALL, V. T.; JURBERG, P.; ALMEIDA, E. M.; CASZ, C.; CAVALCANTE, F. G. \& BASNO, S., 1987b. Educação em saúde para alunos do $1^{9}$ grau. Avaliaçăo de material para ensino $e$ profilaxia da esquistossomose. Revista de Saúde Pública, 21: 387-404.

SCHALL, V. T.; JURBERG, P.; BORUCHOVITCH, E.; FÉLIX-SOUZA, I. C.; ROZEMBERG, B. \& VASCONCELOS, M. C., 1987c. Health education for children. Developing a new strategy. In: Proceedings of the Second International Seminar: Misconceptions and Educational Strategies in Science and Mathematics. (J. D. Novak, org.), vol II., pp. 388-403, Ithaca: Cornell University.

SCHALL, V. T.; MOHR, A.; BARBIERI, M. R.; CARVALHO, C. P. \& BENDATI, M. M., 1992. Educação, saúde e meio ambiente. In: Conferéncia Internacional de Meio Ambiente, Desenvolvimento e Saúde (CIMADES): Carta da Saúde, Agenda Sanitária e Relatórios Finais, pp. 25-29. Rio de Janeiro: Fundação Oswaldo Cruz.

VARGAS, C. D.; MINTZ, V. \& MEYER, M. A. A., 1988. O corpo humano no livro didático ou de como o corpo didático deixou de ser humano. Educação em Revista, 8: 12-18. 